\title{
ANÁLISES ESTATÍSTICAS DE TENDÊNCIAS DAS SÉRIES HIDRO-CLIMÁTICAS E DE AÇÕES ANTRÓPICAS AO LONGO DAS SUB-BACIAS DO RIO TIETÊ
}

\author{
D. H. L. FERREIRA * , J. C. PENEREIRO e M. R. FONTOLAN \\ Pontifícia Universidade Católica de Campinas \\ lombardo@puc-campinas.edu.br
}

Artigo submetido em maio/2013 e aceito em abril/2015

DOI: $10.15628 /$ holos.2015.1455

\section{RESUMO}

O objetivo deste estudo foi realizar análises estatísticas para identificar possíveis ocorrências de tendências em séries anuais de temperatura média do ar, precipitação pluviométrica e vazão de rios, registradas em cinco localidades que pertencem as sub-bacias hidrográficas do rio Tietê, no estado de São Paulo, Brasil. Foram empregados dados climáticos do Centro Integrado de Informações Agrometeorológicas (CIIAGRO) do Instituto Agronômico de Campinas (IAC), além dos dados hidrológicos do Sistema de Informações para o Gerenciamento de Recursos Hídricos do Estado de São Paulo (SIGRH). Para cada série histórica foram realizadas análises de regressão linear e os testes não paramétricos de Run, Mann-Kendall e Pettitt. Os resultados confirmam que dos cinco locais avaliados dois apresentaram tendência positiva na temperatura média e um na vazão. Somente uma localidade apresentou tendência negativa na precipitação pluviométrica. Adicionalmente, procurou-se verificar possíveis correlações devido aos impactos causados pelas construções de barragens, desmatamentos e o aumento populacional sobre as variáveis hidro-climáticas aqui avaliadas.

PALAVRAS-CHAVE: tendência hidro-climática, testes estatísticos, ações antrópicas, educação ambiental

\section{STATISTICAL ANALYSIS OF TRENDS IN ANNUAL SERIES OF HYDRO-CLIMATIC DATA AND ANTHROPOGENIC ACTIONS ALONG OF THE SUB-BASINS IN THE TIETÊ RIVER}

\author{
ABSTRACT \\ The aim of this study was to perform statistical analysis \\ to identify possible trends, in annual time series, of \\ average temperature of air, rainfall and flow of rivers, \\ registered in five locations that belong to some sub- \\ basins of the Tietê river, in São Paulo state, Brazil. The \\ climate measurements employed were made by the \\ Centro Integrado de Informações Agrometeorológicas \\ (CIIAGRO) of the Instituto Agronômico de Campinas \\ (IAC), in addition to the hydrological data from the \\ Sistema de Informações para o Gerenciamento de \\ Recursos Hídricos do Estado de São Paulo (SIGRH). For
}

each historical series linear regression analyses and nonparametric tests of Run, Mann-Kendall and Pettitt were conducted. The results confirm that considering the five locations evaluated two accused instances of positive trends in average temperature and in rainfall. Only a location presented negative trend in precipitation. Additionally, we tried to check possible correlations due to the impacts caused by the construction of dams, deforestation and population growth on the hydro-climatic variables here evaluated.

KEYWORDS: hydro-climatic trend, statistical tests, anthropogenic actions, environmental education 


\section{INTRODUÇÃO}

A utilização da Matemática e/ou Estatística auxiliando na interpretação de diversos fenômenos da natureza pode atuar no favorecimento de tomadas de decisões mais objetivas e coerentes. As várias alterações nas características naturais decorrentes do desenvolvimento insustentável provocam diversas modificações no ambiente. Os meios de comunicação têm enfatizado os diversos problemas ambientais buscando despertar a sensibilização das pessoas para a sua importância. Um dos problemas ambientais de grande relevância está relacionado ao clima, pois ele exerce influência direta nos processos, tanto de ordem física quanto biológica, afetando a sociedade de um modo geral, visto que constitui num recurso essencial para a vida e para as atividades humanas (CHRISTOFOLETTI, 1993).

As mudanças climáticas nos regimes de temperatura e precipitação pluviométrica também podem ser provocadas pela interferência do homem no meio ambiente, especialmente devido aos grandes desmatamentos e queimadas (SERRA FILHO et. al., 1975), além da crescente urbanização sem o planejamento adequado que vem ocorrendo nas últimas décadas (KARL et. al., 1988).

A relação entre o aquecimento atmosférico, as mudanças climáticas globais e seus efeitos na distribuição dos ecossistemas, implicam em profundas alterações na atual composição da biodiversidade. Neste sentido, Salati et. al. (2004) assinalam que, em um futuro próximo, é esperado um cenário de clima mais extremo com ocorrências mais frequentes de secas, inundações, tempestades tropicais e ondas de calor.

A influência do homem pode provocar mudanças nos níveis da temperatura do ar, possibilitando aumentar a concentração de dióxido de carbono na atmosfera advindo, principalmente, da queima de combustíveis fósseis e do desflorestamento; além da quantidade de partículas em suspensão causada pela produção industrial excessiva (VAREIJÃO-SILVA, 2001). Além disso, a vazão de um rio também pode ser afetada, pois ela resulta de uma complexa interação dos diversos processos de armazenamento e transporte do ciclo hidrológico, dependendo da capacidade de infiltração do solo e da frequência de chuvas.

A realização de medições de índices de precipitação pluvial é importante em diferentes contextos, tais como, produção de alimentos, manejo dos recursos hídricos, avaliação ambiental, erosão hídrica, dentre outros. A obtenção da correta distribuição espacial para precipitação é relevante no planejamento agrícola, no que diz respeito à instalação de novas áreas de manejo. Além da influência na agricultura, períodos de estiagens muito longos afetam o nível de água dos mananciais e dos reservatórios das usinas hidrelétricas, trazendo graves consequências para o abastecimento urbano e para a geração de energia elétrica. Não obstante, a quantificação das chuvas com intensidades superiores ao suporte do ambiente é importante para um correto dimensionamento das obras, tanto na construção civil quanto na conservação do solo (VIEIRA; CARVALHO, 2001). Como destaca Carlos Nobre em reportagem veiculada à National Geographic Brasil, "com o planeta aquecido, poderá haver secas mais drásticas no Brasil". Segundo esse climatologista, "a poluição do ar nas grandes cidades vai se agravar e ondas de calor frequentes também podem aumentar a área de transmissão de doenças tropicais" (MILLER, 2012, p. 103). 
A vazão de um curso d'água é de primordial importância, pois influencia no comportamento do rio e de ecossistemas interligados a ele, como as matas ciliares. De acordo com Mortatti et al. (2004), as séries temporais de vazão são os resultados das integrações dos componentes do ciclo hidrológico e, consequentemente, das influências naturais e antrópicas de uma determinada região. Para esses autores, estas séries têm fundamental importância, pois oferecem subsídios para a tomada de decisões em relação à racionalização do uso da água, além da preservação deste recurso. Nesta mesma direção, Cervilha e Filho (2011) assinalam que resultados de qualidade da previsão das vazões possibilitam realizar o planejamento energético, de modo a atingir bons níveis na geração de energia hidroelétrica.

Sensibilizados, por essas questões, o presente trabalho foi direcionado no sentido de estudar as temperaturas, as precipitações pluviométricas e as vazões de rios ao longo do percurso do rio Tietê. Este rio é famoso por sua grande extensão (1.100 quilômetros), com sua nascente situada na cidade de Salesópolis (dentro da região metropolitana da capital paulista), atravessando todo o estado de São Paulo de norte a sul. O rio Tietê é de vital importância, pois nele se situam barragens e usinas hidrelétricas que contribuem para a geração de energia da grande São Paulo, além do que, em alguns trechos, o mesmo é utilizado para a navegação pluvial, movimentando toneladas de grãos ao longo das safras agrícolas. Embora seja um dos rios mais importantes economicamente para o estado de São Paulo, ele também é conhecido pelos seus problemas ambientais, pois vem sofrendo os impactos impostos pela poluição ocasionada, na maioria das vezes, pelo crescimento desordenado das cidades próximas às margens.

Teve-se como meta compreender, por meio de análises estatísticas, a evolução das séries de dados hidro-climáticos ao longo do tempo, identificando se estas variáveis apresentam tendências significativas, e, em caso afirmativo, a partir de quando iniciou essa ocorrência. Desta maneira, julga-se que estudos desta natureza possam contribuir para uma reflexão a respeito dos impactos ambientais em diversos setores da sociedade, sobretudo aqueles vinculados à agricultura ou ao saneamento básico.

\section{MATERIAIS E MÉTODOS}

A partir das medidas disponíveis no Centro Integrado de Informações Agrometeorológicas do Instituto Agronômico de Campinas - IAC (CIIAGRO, 2012) e no Sistema de Informações para o Gerenciamento de Recursos Hídricos do Estado de São Paulo - SIGRH (SIGRH, 2011), foi possível trabalhar com amostras de dados desejados para os estudos estatísticos. Diante dessa possibilidade, obteve-se uma extensa base de dados relacionados às variáveis climáticas das temperaturas médias e de precipitações pluviométricas, além dos índices de vazões, de cinco municípios localizados no estado de São Paulo que se situam nas proximidades da calha do rio Tietê.

As localizações aproximadas das cidades estão indicadas no mapa da Figura 1, respeitando a identificação da Tabela 1 e as respectivas bacias a que pertencem. A figura também apresenta a localização das barragens nessa região numeradas de (a) até (e). 


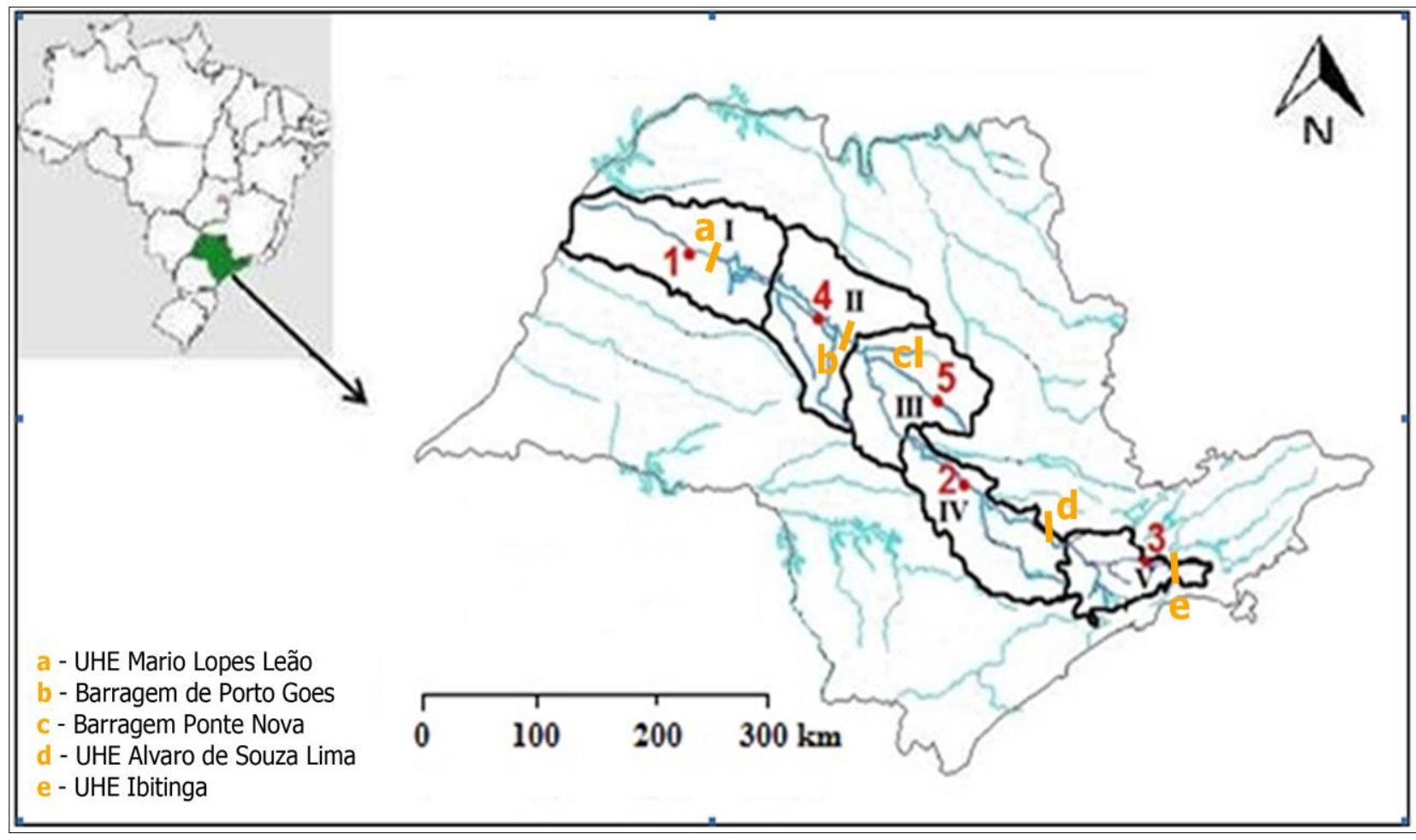

Figura 1 - Locais no estado de São Paulo por onde atravessa o rio Tietê e suas sub-bacias hidrográficas: I - Alto Tietê; II - Tietê/Batalha; III - Tietê/Jacaré; IV - Tietê/Sorocaba e V- Baixo Tietê.

Na Tabela 1 são mostrados os nomes dos municípios nos quais se encontram as estações de medição do IAC e as bacias hidrográficas, assim como suas coordenadas (latitude e longitude), as variáveis estudadas ( $\mathrm{T}$ - temperatura média do $\mathrm{ar}, \mathrm{P}$ - precipitação pluviométrica, $\mathrm{V}$ - vazão do rio), os períodos das séries históricas e a identificação.

Com o intuito de avaliar preliminarmente o comportamento da série temporal anual associada a um determinado parâmetro climático foi feito o cálculo das médias móveis, empregando ordem cinco aos dados. Posteriormente, visando evitar possíveis flutuações, trabalhou-se com uma suavização dos dados, seguindo a sugestão de Sello (1999), que utilizou a seguinte relação para uma dada série temporal:

$$
\bar{V}_{n}=\frac{1}{6}\left[\sum_{j=n-2}^{n+2} V_{j}+\frac{1}{2}\left(V_{n+3}+V_{n-3}\right)\right]
$$

onde $\left(\bar{V}_{n}\right)$ representa o valor médio de uma dada variável em estudo para o i-ésimo ano $\left(V_{i}\right)$.

Foram aplicados o teste paramétrico da análise de regressão linear e os testes não paramétricos de Mann-Kendall, Pettitt e Run.

$\mathrm{Na}$ análise de regressão linear utilizou-se a equação da reta da tendência $(Y=a(x)+b)$, onde $a$ é o coeficiente angular da reta e, no caso, $x=t$. Assim, se $a>0$ significa que a tendência é crescente e, se caso $a<0$ indica uma tendência decrescente. Ao realizar esse procedimento, o valor da estatística do R-quadrado $\left(R^{2}\right)$ é devolvido como uma medida da qualidade do ajuste efetuado. Complementando essa análise, determinou-se o intervalo de confiança em $95 \%$ acima e abaixo do valor estimado do coeficiente angular da reta de regressão. 
Tabela 1 - Localização dos municípios trabalhados nesta pesquisa.

\begin{tabular}{|c|c|c|c|c|c|}
\hline Município & Latitude & Longitude & Variável & Série & Identificação \\
\hline \multirow[t]{2}{*}{ Araçatuba } & 21으익 & $50 \div 28^{\prime}$ & Temperatura & 1997 a 2011 & $1 T$ \\
\hline & & & Precipitação & 1957 a 2004 & $1 \mathrm{P}$ \\
\hline (rio Tietê) & 21은 & $50 \div 23^{\prime}$ & Vazão & 1971 a 1979 & $1 \mathrm{~V}$ \\
\hline \multirow[t]{2}{*}{ Tatuí } & $23^{\circ} 22^{\prime}$ & $47^{\circ} 52^{\prime}$ & Temperatura & 1954 a 2010 & $2 T$ \\
\hline & & & Precipitação & 1938 a 2010 & $2 P$ \\
\hline (rio Sorocaba) & 23이' & $47^{\circ} 27^{\prime}$ & Vazão & 1969 а 2003 & $2 \mathrm{~V}$ \\
\hline \multirow{2}{*}{ Mogi das Cruzes } & 23ㅇ' & $46 \div 10^{\prime}$ & Temperatura & 1983 a 2010 & $3 T$ \\
\hline & & & Precipitação & 1983 a 2010 & $3 \mathrm{P}$ \\
\hline (rio Tietê) & $26031^{\prime}$ & $46012^{\prime}$ & Vazão & 1965 a 2004 & $3 \mathrm{~V}$ \\
\hline \multirow[t]{2}{*}{ Reginópolis } & $21^{\circ} 53^{\prime}$ & $49^{\circ} 14^{\prime}$ & Temperatura & 1995 a 2010 & $4 \mathrm{~T}$ \\
\hline & & & Precipitação & 1943 a 1999 & $4 \mathrm{P}$ \\
\hline (rio Batalha) & $21^{\circ} 53^{\prime}$ & $49^{\circ} 14^{\prime}$ & Vazão & 1943 a 1999 & $4 \mathrm{~V}$ \\
\hline \multirow[t]{2}{*}{ Araraquara } & $22^{\circ} 01^{\prime}$ & $47^{\circ} 54^{\prime}$ & Temperatura & 1993 a 2011 & $5 T$ \\
\hline & & & Precipitação & 1936 a 1998 & $5 P$ \\
\hline (rio Jacaré Guaçú) & $21^{\circ} 52^{\prime}$ & $48^{\circ} 17^{\prime}$ & Vazão & 1969 a 2004 & $5 \mathrm{~V}$ \\
\hline
\end{tabular}

O teste não paramétrico sequencial de Mann-Kendall, proposto inicialmente por Sneyers (1975), é o método mais apropriado para analisar mudanças climáticas e, segundo Goossens e Berger (1986), ele permite detectar e localizar de forma aproximada o ponto inicial de determinada tendência. Neste teste, considera-se que, na hipótese de estabilidade de uma série de dados, a sucessão de valores ocorre de forma independente e a distribuição de probabilidade deve permanecer sempre a mesma (série aleatória simples) (SNEYERS et al., 1990). O método considera uma série $Y_{i}$ de $n$ termos a ser analisada $(1 \leq i \leq n)$. Primeiramente, realiza-se a soma $t_{n}=\sum_{i=1}^{n} m_{i}$ do número de termos $m_{i}$ da série, relativo ao valor $Y_{i}$ cujos termos precedentes $(j<i)$ são inferiores ao mesmo $\left(Y_{j}<Y_{i}\right)$. Para séries com grande número de termos $(n)$, sob a hipótese nula $\left(H_{0}\right)$ de ausência de tendência, $t_{n}$ apresentará uma distribuição normal com média e variância dada, respectivamente, por $E\left(t_{n}\right)=\frac{n(n-1)}{4}$ e $\operatorname{var}\left(t_{n}\right)=\frac{n(n-1)(2 n+5)}{72}$.

Testando a significância estatística de $t_{n}$ para a hipótese nula, usando um teste bilateral, esta pode ser rejeitada para grandes valores da série estatística $U\left(t_{n}\right)$ por meio da equação dada por:

$$
U\left(t_{n}\right)=\frac{\left[t_{n}-E\left(t_{n}\right)\right]}{\sqrt{\operatorname{var}\left(t_{n}\right)}}
$$

Após a determinação dos valores de $U\left(t_{n}\right)$ verifica-se o valor da probabilidade $\alpha_{1}$, $\alpha_{1}=\operatorname{prob}\left(|U|>\left|U\left(t_{n}\right)\right|\right)$, calculada por meio de uma tabela da normal reduzida. Considerando $\alpha_{0}$ o nível de significância do teste, a hipótese nula é aceita se $\alpha_{1}>\alpha_{0}$. Caso a hipótese nula seja rejeitada, implicará a existência de tendência significativa, sendo que o sinal da estatística $U\left(t_{n}\right)$ indica se a tendência é decrescente $\left(U\left(t_{n}\right)<0\right)$ ou então crescente $\left(U\left(t_{n}\right)>0\right)$. Neste caso, em sua versão sequencial, a equação $U\left(t_{n}\right)$ é calculada no sentido direto da série, partindo do valor $i=1$ até $i=n$ gerando a estatística $-1,65<U\left(t_{n}\right)<+1,96$. Neste caso, admitiu-se que os 
valores dos intervalos bilaterais -1,65 a +1,65 e -1,96 a +1,96, correspondentes aos níveis de significância para $\alpha_{0}=0,10$ (em 10\%) e $\alpha_{0}=0,05$ (em 5\%), respectivamente.

O ponto de início de uma mudança na série pode ser determinado aplicando-se, de forma análoga, porém no sentido inverso da série temporal original, isto é, a partir do valor $i=n$ até $i=1$, o cálculo da estatística inversa $U^{*}\left(t_{n}\right)$. A interseção das duas curvas estatísticas $U\left(t_{n}\right)$ e $U^{*}\left(t_{n}\right)$ corresponde ao local aproximado do ponto de mudança de tendência, que pode ser avaliado graficamente. Entretanto, isso só é significativo caso este ponto ocorra dentro do intervalo de significância bilateral, isto é, entre-1,65 a +1,96.

O teste não paramétrico de Pettitt (PETTITT, 1979) é um teste estatístico utilizado para identificar o ponto de descontinuidade em uma série temporal. O procedimento consiste em avaliar se a série temporal, submetida a um teste de homogeneidade de duas subamostras, $Y_{1}, \ldots, Y_{t} \mathrm{e} Y_{t+1}, \ldots, Y_{T}$, pertencem à mesma população. Para tanto, a série foi ordenada de 1 a $n$ de acordo com sua posição de observação $t$. Uma contagem do número de vezes que um membro da primeira amostra é maior que o membro da segunda é realizado por intermédio do cálculo:

$$
U_{t, T}=U_{t-1, T}+\sum_{j=1}^{T} \operatorname{sgn}\left(Y_{i}-Y_{j}\right) ; \text { para } t=2, \ldots ., T
$$

onde $\operatorname{sgn}(x)=1$ para $x>0 ; \operatorname{sgn}(x)=0$ para $x=0$ e $\operatorname{sgn}(x)=-1$ para $x<0$.

A estatística $U_{t, T}$ é então calculada para valores de $1 \leq t \leq T$, sendo que a estatística $K(t)$ do teste fornece o máximo valor absoluto de $U_{t, T}$, por meio da equação $K_{T}=\max _{1 \leq t \leq T}\left|U_{t, T}\right|$ (PETTITT, 1979).

A estatística assim desenvolvida localiza o ponto em que houve uma mudança brusca na média de uma série, o valor para $t$ onde ocorre o máximo de $K(t)$.

$$
K_{\text {crit. }}= \pm \sqrt{\frac{-\ln (p / 2)\left(T^{3}+T^{2}\right)}{6}}
$$

Com isso, é possível localizar o ponto onde ocorre uma mudança brusca $(t)$ na série temporal, além da sua significância estatística $(p)$. Para tanto, utiliza-se a expressão $p=$ $2 e^{\frac{-6 K_{t}^{2}}{\left(T^{3}+T^{2}\right)}}$

O teste possui como hipótese nula $\left(H_{0}\right)$ a não existência de mudança brusca na série enquanto a hipótese alternativa $\left(H_{1}\right)$ existir. Para haver rejeição o valor crítico de $K_{t}$ é determinado para um nível de significância $\alpha_{0}$ por meio da equação:

$$
K_{\text {crit. }}= \pm \sqrt{\frac{-\ln (p / 2)\left(T^{3}+T^{2}\right)}{6}}
$$

no qual $K_{\text {crit. }}$. está relacionado ao instante em que ocorreu a mudança brusca $(t)$. Neste caso, admitiram-se os níveis de significância em 5\% e 10\%.

Do exposto acima, ressalta-se que quando no teste Mann-Kendall houver interseção das duas curvas estatísticas $U\left(t_{n}\right)$ e $U^{*}\left(t_{n}\right)$, entre os intervalos de significâncias de $\pm 5 \%$ a $\pm 10 \%$ e, adicionalmente, a curva da estatística $K_{(t)}$ no teste Pettitt também cruzar os níveis de significância de $5 \%$ a $10 \%$ do valor calculado para $K_{\text {crit. }}$ a ocorrência da "quebra" na série 
temporal então fica confirmada, e assim admite-se a existência de tendência com a possibilidade de localizar a data dessa ocorrência. Caso algum desses critérios seja violado, nada pode ser afirmado a respeito da existência de tendência nos dados da série temporal trabalhada.

O teste não paramétrico Run (THOM, 1966), consiste em realizar a contagem do número de oscilações dos valores acima e abaixo da mediana, numa série de dados ordenada. O número de oscilações é chamado de Run, e deve-se testar se o valor observado está dentro da faixa de distribuição considerada normal. Se a sequência contém $N 1$ símbolos de um tipo, e $N 2$ símbolos de outro tipo (e $N 1$ e $N 2$ não são muito pequenos), a distribuição amostral do número de Runs total pode ser aproximada pela distribuição normal com média $E(u)=$ $\frac{2(N 1)(N 2)}{(N 1)+(N 2)}+1$ e variância $\operatorname{Var}(u)=\frac{2 N 1 N 2(2 N 1 N 2-N 1-N 2)}{(N 1+N 2)^{2}(N 1+N 2-1)}$, onde u representa o número de Runs. A hipótese nula de que a distribuição dos símbolos ocorre normalmente, e que a amostra é aleatória, pode ser testada com base na estatística: $Z=\frac{u-E(u)}{\sqrt{\operatorname{var}(u)}}$. Para o nível de significância de $5 \%, Z$ deve estar entre $-1,96$ e 1,96. Caso $Z$ calculado seja maior que o valor tabelado, deve-se rejeitar a hipótese de nulidade.

\section{RESULTADOS E DISCUSSÕES}

\subsection{ANÁLISES DE TENDÊNCIAS}

Diferentes procedimentos foram realizados usando recursos disponíveis no Microsoft Excel, em particular aquele visando a formatação, funções aritméticas e lógicas, funções estatísticas, ajustes de curvas, gráficos, dentre outros.

Optou-se ao longo deste trabalho por apresentar alguns resultados em forma gráfica, porém, complementando a esses, decidiu-se apresentar tabelas resumindo as informações obtidas nas análises estatísticas efetuadas para cada série histórica.

Primeiramente, fez-se uso da estatística paramétrica para verificar a ocorrência de possível tendência de uma série seguindo a linha proposta por Penereiro e Ferreira (2011). Os gráficos da Figura 2 mostram os resultados das análises de regressão linear aplicados aos dados de temperatura média do ar, na localidade do município de Tatuí, entre 1954 e 2010. Esses gráficos revelam acréscimos dessa grandeza, pois os valores dos coeficientes angulares são positivos $(a>0)$, tanto para média móvel (Figura 2a) como para suavização aos dados (Figura 2b). A equação linear e a qualidade do ajuste $\left(R^{2}\right)$, em cada situação, estão indicadas na parte inferior de cada gráfico.
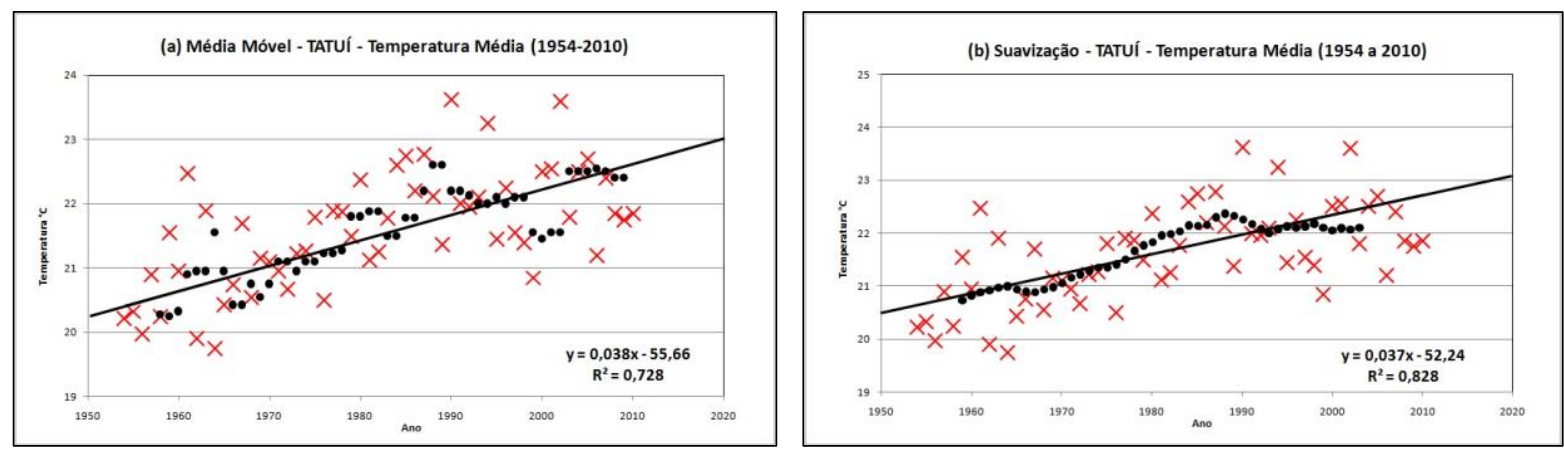
Figura 2 - Análise da regressão linear aplicada aos pontos interligados das médias móveis (a) e suavizados (b) para os dados de temperatura média (pontos em vermelho) na cidade de Tatuí entre 1954 e 2010.

De forma análoga, nos gráficos da Figura 3 encontram-se os comportamentos para o índice de precipitação pluviométrica para a cidade de Araçatuba no período entre 1964 e 2004. Nesses casos, verificam-se comportamentos estáveis para a média móvel (Figura 3a) e a suavização (Figura $3 b$ ), pois os coeficientes angulares são próximos de zero $(a \approx 0)$, significando não haver indícios de tendências para essas séries.
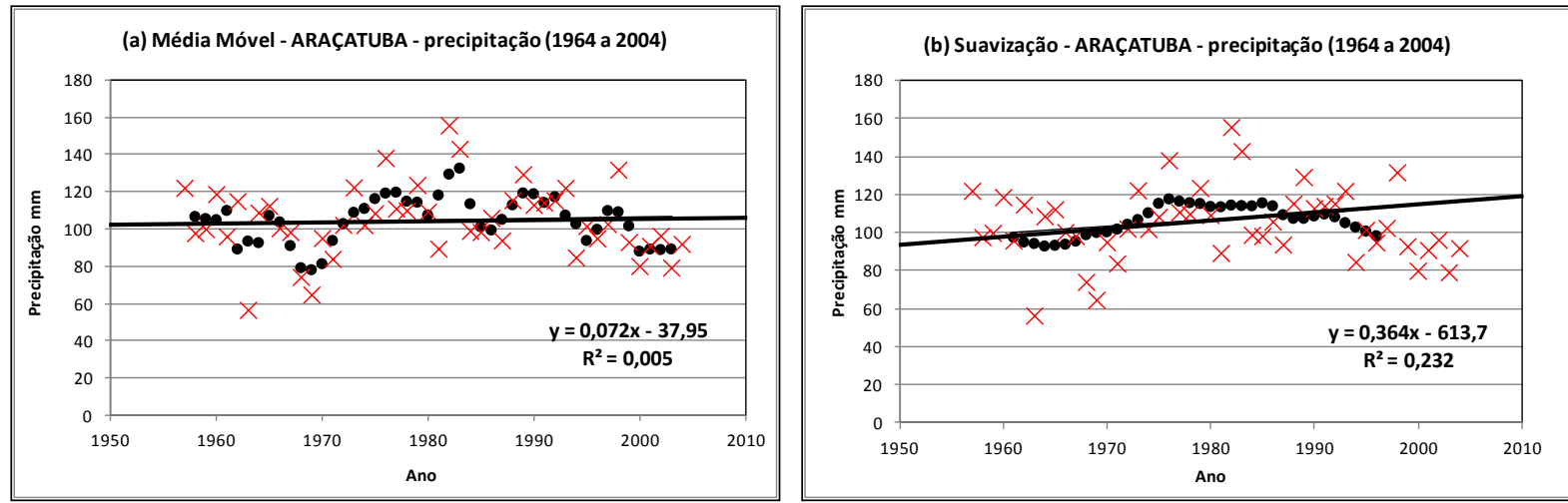

Figura 3 - Idem ao da Figura 2, porém para precipitação pluviométrica na cidade de Araçatuba entre 1964 e 2004.

Foram encontrados comportamentos decrescentes $(a<0)$ para o índice de vazão do rio Tietê na localidade de Mogi das Cruzes no período entre 1965 e 2003, como revelam os gráficos da média móvel (Figura 4a) e da suavização (Figura 4b).
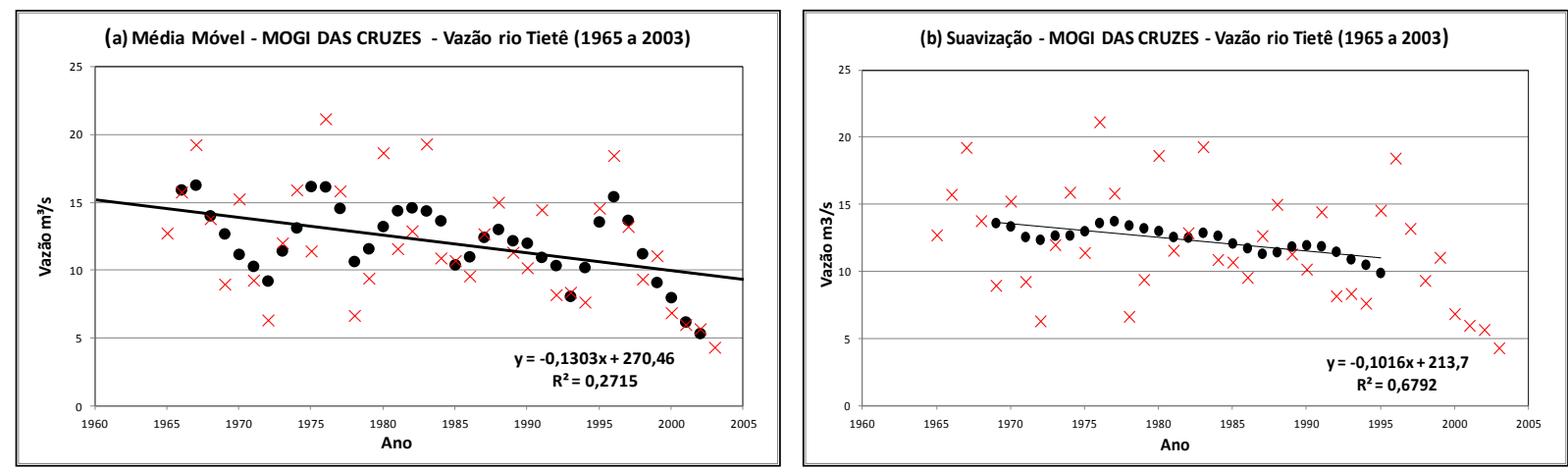

Figura 4 - Idem aos das Figuras 2 e 3, porém para a vazão do rio Tietê em Mogi das Cruzes, no período de 1965 a 2003.

Comparando os gráficos anteriores, usados aqui a título de demonstração, é possível verificar que as séries históricas tratadas pela suavização possuem menor flutuação do que quando tratadas por meio da média móvel. Isso pode ser comprovado pelos valores de $R^{2}$, uma vez que quanto mais próximo da unidade, menor a dispersão dos dados e, consequentemente, melhor o ajuste realizado.

Embora a análise da regressão linear descrita parcialmente acima possa, em princípio, representar possibilidades de eventuais tendências dos parâmetros estudados, os intervalos de confiança empregados para esse tipo de análise tornam-se limitados para tomar a decisão se determinada série histórica sofre ou não tendência. A mesma situação ocorreu para as demais localidades, como se verifica nas informações contidas na Tabela 2, juntamente com os valores 
do $R^{2}$. Tendo em vista essas limitações e com a finalidade de obter análises mais confiáveis decidiu-se empregar os testes não paramétricos de Run, Mann Kendall (MK) e Pettitt (P).

A seguir são apresentados os gráficos referentes aos testes de MK e P aplicados a algumas séries históricas trabalhadas neste estudo. Em ambos os testes, as linhas horizontais pontilhadas representam os limites críticos dos intervalos de confiança de $90 \%$ e as linhas tracejadas com intervalos de confiança de $95 \%$. Vale ressaltar que no teste MK uma tendência é significativa quando os valores absolutos de $U\left(t_{n}\right)$ são maiores que os intervalos de confiança e o início dessa tendência pode ser identificado pela interseção das curvas $U\left(t_{n}\right)$, representados em traçados contínuos, e $U^{*}\left(t_{n}\right)$, representados por traçados descontínuos. Entretanto, isso deve ocorrer dentro dos valores críticos dos intervalos de confiança (GROPPO et al., 2005; PENEREIRO; FERREIRA, 2011). De maneira diferente, no teste $P$ o ponto de mudança brusca da estatística $K(t)$, medida em módulo, ocorre quando este for maior que os limites críticos estabelecidos. No entanto, essa condição deixa de ser verdadeira quando os valores que estão em seguida ao valor crítico oscilam em intervalos próximos ao valor máximo. Neste caso, o último valor do intervalo de oscilação indica o ponto de início da tendência (PETTITT, 1979).

Os gráficos da Figura 5 mostram os comportamentos para a série histórica do índice de temperatura média do ar da cidade de Tatuí no período de 1954 a 2010 aplicando os testes de MK e P. Verifica-se que o teste MK (Figura 5a) acusou cruzamento das curvas estatísticas de $U\left(t_{n}\right)$ e $U^{*}\left(t_{n}\right)$ entre os intervalos de confiança. Esse cruzamento, ocorrido em 1972, indica indício de haver tendência nessa variável nesta data. Porém, somente essa constatação não é suficiente para afirmar se ocorreu de fato tendência nessa variável, tornando necessário o uso do teste $\mathrm{P}$ (Figura $5 \mathrm{~b}$ ). Identifica-se, pelo gráfico da Figura $5 \mathrm{~b}$, que o valor da estatística $K(t)$ cruzou o intervalo de confiança no ano de 1972, confirmando, desta maneira, tendência de crescimento para a temperatura média do ar em Tatuí naquele ano.

De maneira análoga, os gráficos da Figura 6 mostram as formas gráficas dos testes MK e P para a série histórica do índice de precipitação pluviométrica da cidade de Araçatuba no período de 1957 a 2004. É possível verificar que o teste MK (Figura 6a) acusou cruzamentos das curvas estatísticas entre os intervalos de confiança, dando indícios de haver tendência nessa variável, porém numa data indefinida. Entretanto, ao aplicar o teste $P$ (Figura $6 \mathrm{~b}$ ) verifica-se que não ocorreu cruzamento da estatística $K(t)$ no intervalo de confiança, descartando qualquer possibilidade da ocorrência de tendência na precipitação pluviométrica em Araçatuba.
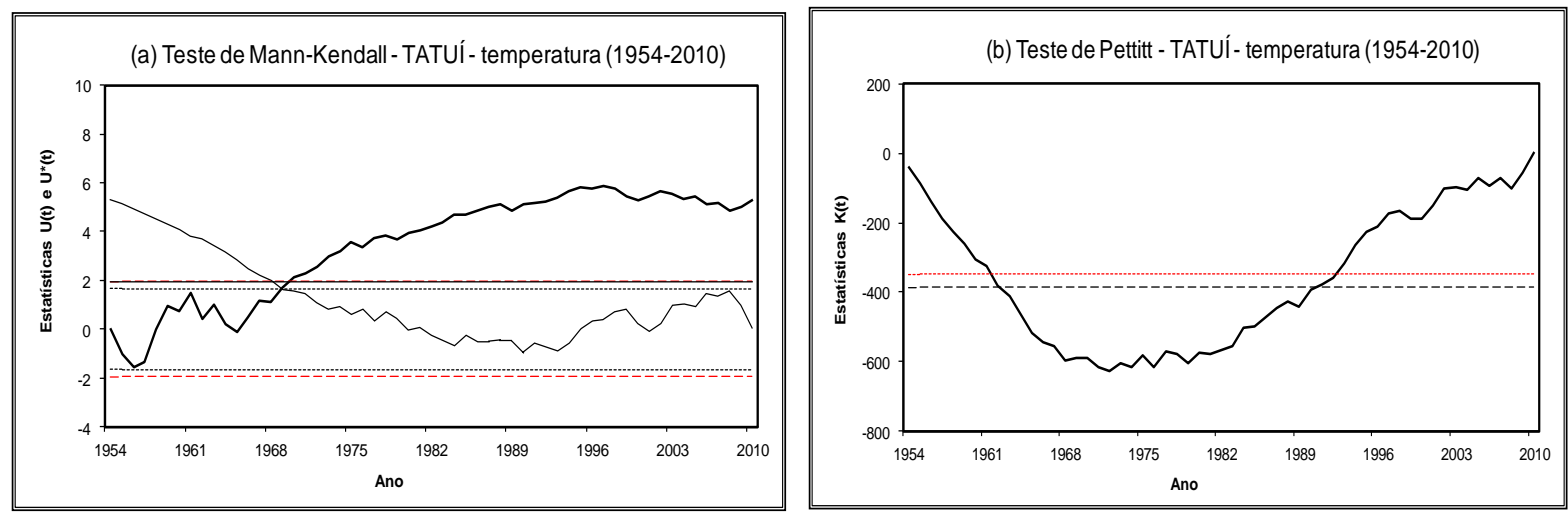

Figura 5 - (a) Testes de Mann-Kendall e (b) Pettitt para os dados de temperatura média do ar na cidade de Tatuí. 

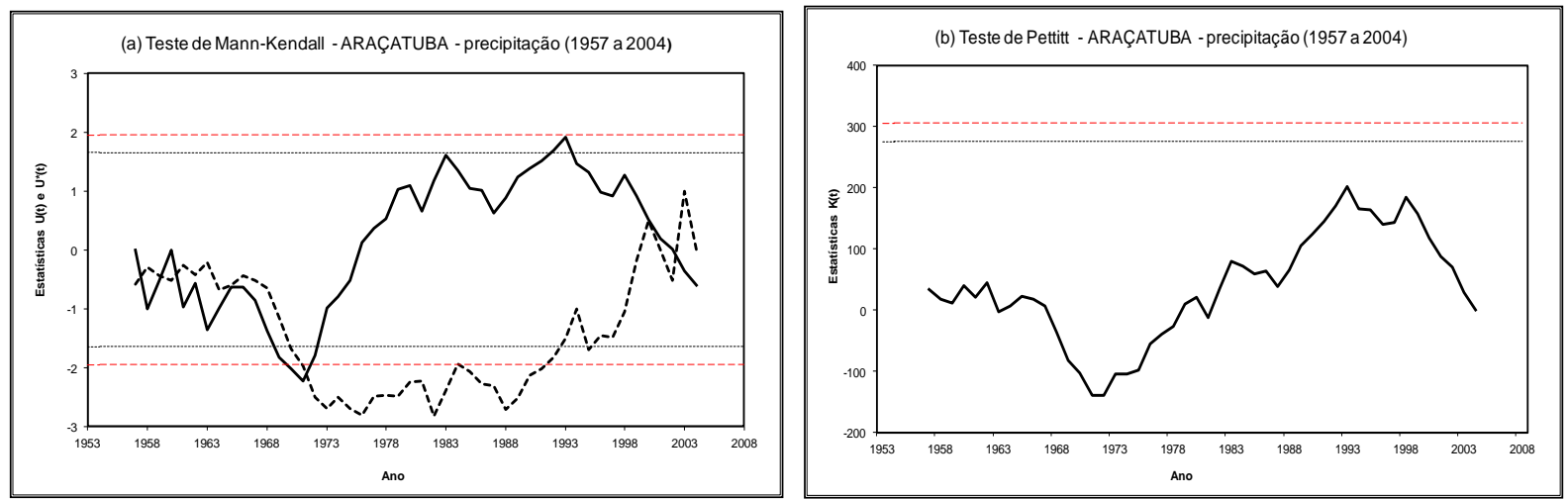

Figura 6 - Idem ao da figura anterior, porém para os dados de precipitação pluviométrica na cidade de Araçatuba.

Os gráficos da Figura 7 mostram os comportamentos dos testes MK e P para a série histórica do índice de vazão do rio Batalha, no município de Reginópolis, entre 1943 e 1999. Constata-se que não ocorreu nenhum cruzamento das curvas estatísticas entre os intervalos de confiança no teste $\mathrm{MK}$, em que pese a estatística $K(t)$ ter cruzado os intervalos de confiança no teste P. Assim, pode-se afirmar que não existe evidência de tendência para a vazão do rio Batalha, afluente do rio Tietê.
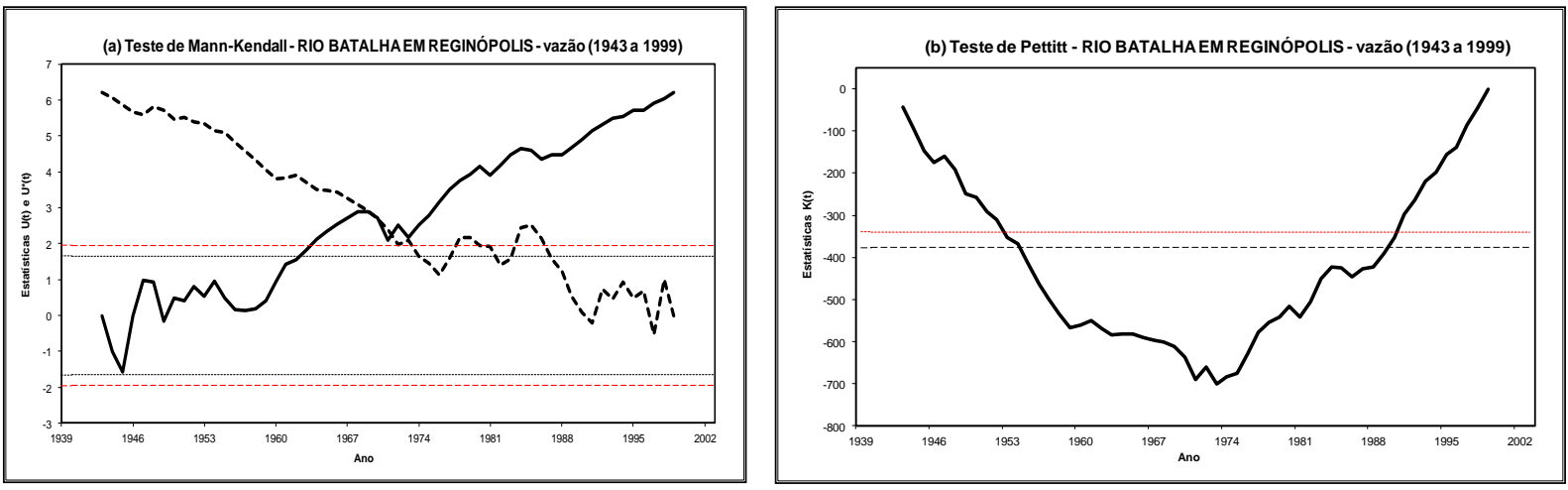

Figura 7 - Idem, para os dados de vazão do rio Batalha (Reginópolis).

Análises estatísticas semelhantes foram realizadas para todas as séries históricas citadas na Tabela 1. Um resumo de todas as informações obtidas a partir dos procedimentos de reduções de dados empregando os testes estatísticos está contido na Tabela 2. Nessa tabela são indicados, para as mesmas variáveis da Tabela 1 , os valores do coeficiente angular $(a)$, da qualidade do ajuste $\left(R^{2}\right)$, do intervalo de confiança em $95 \%$, os resultados extraídos pelo emprego dos testes de Run (o valor de Z calculado), de Mann-Kendall e de Pettitt. Nestes dois últimos testes foram adotados os resultados como "dentro" (se a tendência se confirma dentro dos limites críticos dos intervalos de confiança bilateral) ou "fora" (no caso de não se confirmar tendência). Finalmente, o resultado final da ocorrência de tendência está indicado na última coluna da tabela, sendo adotada a seguinte convenção: (NC) "não confirmada", (+C) "confirmada com aumento da tendência" e $(-C)$ "confirmada com diminuição da tendência", além do ano de ocorrência desta.

Dentre as cinco localidades analisadas pelos procedimentos de regressão linear, com exceção do município de Araçatuba, em todas as outras foram detectados indícios de aumento nos índices de temperatura média do ar $(a>0)$. Para as séries históricas de precipitação pluviométrica, todas as localidades acusaram indícios de aumento nos índices dessa variável 
climática. Quanto às séries históricas de vazão do rio, exceto para o rio Tietê na localidade do município de Mogi das Cruzes que apresentou $a<0$, todos os outros valores de vazão acusaram indícios de aumento nos índices dessa variável.

Em relação a qualidade dos ajustes realizados por meio da regressão linear, numa simples análise da Tabela 2 é possível identificar que a amostra das séries históricas trabalhada apresentou uma ampla gama de valores, situando-se no intervalo entre 0,0139, para a precipitação pluviométrica de Araraquara, e 0,9975 para a temperatura média do ar de Araçatuba. Como antes assinalado, pode-se perceber que os ajustes realizados na suavização, em geral, são melhores que aqueles realizados com a média móvel.

No que concerne ao intervalo de confiança (IC), que representa a probabilidade do coeficiente angular $(a)$ de uma variável encontrar-se no intervalo calculado de $95 \%$ dos dados, os valores encontrados dependem da variável hidro-climática que está sendo tratada. Por esta razão ocorreu uma grande distribuição de intervalos, como mostrados na Tabela 2.

Segundo Back (2001), para que haja uma possível tendência ao aplicar o teste de Run é necessário que o valor de $Z$ calculado esteja fora do intervalo ao nível de $5 \%$ de significância. Diante dos resultados apresentados na Tabela 2, tanto o índice de temperatura média da cidade de Tatuí $(-2,8509)$ e de Reginópolis $(-2,0702)$, quanto o índice de vazão do rio Batalha $(-2,4316)$ e do rio Jacaré Guaçú $(-3,7292)$ satisfizeram essa condição, indicando possível tendência desta variável nas localidades onde foram coletadas as medições. As medidas de temperaturas médias, precipitações pluviométricas e de vazões dos rios registradas pelas outras estações medidoras não acusaram valores significativos do valor de $Z$ calculado, indicando não haverem tendências por meio do emprego deste teste não paramétrico.

No entanto, Goossens e Berger (1986) afirmam que o teste sequencial de Mann-Kendall é o método mais apropriado para analisar mudanças climáticas numa série histórica. Isso ocorre por que este teste permite detectar e localizar, de forma aproximada, o ponto inicial de uma determinada tendência. Além disso, neste teste se considera que, na hipótese de estabilidade de uma série de dados, a sucessão de valores ocorre de forma independente e a distribuição de probabilidade deve permanecer sempre a mesma (série aleatória simples). Curiosamente, observou-se que, ao reduzir os dados por meio do teste MK, para todas as localidades foram acusadas tendências em duas variáveis climáticas, a temperatura média e a precipitação, visto que ocorreram cruzamentos das curvas estatísticas $U\left(t_{n}\right)$ e $U^{*}\left(t_{n}\right)$ (SNEYERS et al., 1990). Apenas não ocorreram cruzamentos das curvas estatísticas $U\left(t_{n}\right)$ e $U^{*}\left(t_{n}\right)$ para as séries históricas da vazão do rio Batalha e do rio Jacaré Guaçú.

Como comentado anteriormente, uma alternativa adicional às análises dos dados consiste em empregar o teste de Pettitt, essa estatística permite localizar o ponto em que houve uma mudança brusca em uma série (Back, 2001). Ao aplicar este teste nas séries históricas da amostra estudada, constatou-se que em duas localidades, Tatuí e Mogi das Cruzes, foi acusado mudança brusca na temperatura média. Apenas uma, Araraquara, acusou este comportamento na precipitação pluviométrica. Não obstante, em três localidades ocorreram mudança brusca para a vazão, a saber, nos rios Sorocaba em Tatuí, Batalha em Reginópolis e Jacaré Guaçú em Araraquara. 
Concluindo estas análises, ao observar as informações da Tabela 2 e fazendo um cruzamento entre os comportamentos dos testes $M K$ e $P$, verificou-se que, definitivamente, ocorreram tendências confirmadas para aumento da temperatura média do ar em Tatuí, a partir de 1972, e em Mogi das Cruzes, com início em 1993. Da mesma maneira, pode-se dizer que ocorreu um decréscimo no índice da precipitação em Araraquara a partir de 1983 e um aumento na vazão do rio Sorocaba a partir de 1986.

Tabela 2 - Resumo das análises estatísticas paramétricas e não paramétricas aplicadas aos dados suavizados. Em parênteses os ajustes efetuados sobre as médias móveis.

\begin{tabular}{|c|c|c|c|c|c|c|c|}
\hline & \multicolumn{3}{|c|}{ Testes paramétricos } & \multicolumn{4}{|c|}{ Testes não-paramétricos } \\
\hline \# & a & $\mathbf{R}^{2}$ & $\begin{array}{l}\text { Intervalo de } \\
\text { confiança }\end{array}$ & $\begin{array}{l}\text { Teste de Run } \\
\text { ( } Z \text { calculado) }\end{array}$ & Mann-Kendall & Pettitt & Tendência \\
\hline $1 \mathrm{~T}$ & $\begin{array}{c}-0,0121 \\
(-0,0335)\end{array}$ & $\begin{array}{c}0,9975 \\
(0,2726)\end{array}$ & $\begin{array}{c}-0,0197 \text { a }-0,0044 \\
(-0,0698 \text { a } 0,0028)\end{array}$ & $-1,3282$ & dentro & fora & NC \\
\hline $1 P$ & $\begin{array}{c}0,364 \\
(0,0721)\end{array}$ & $\begin{array}{l}0,2327 \\
(0,058)\end{array}$ & $\begin{array}{c}0,1337 \text { a } 0,5943 \\
(-20,465 \text { a } 0,3584)\end{array}$ & $-1,4589$ & dentro & fora & NC \\
\hline $1 \mathrm{~V}$ & $\begin{array}{c}17,7457 \\
(42,1874)\end{array}$ & $\begin{array}{c}0,7474 \\
(0,3746)\end{array}$ & $\begin{array}{c}1,9855 \text { a } 33,5060 \\
(-20,466 \text { a } 104,84))\end{array}$ & 0,4016 & dentro & fora & NC \\
\hline $2 \mathrm{~T}$ & $\begin{array}{c}0,0368 \\
(0,0389)\end{array}$ & $\begin{array}{c}0,8281 \\
(0,7282)\end{array}$ & $\begin{array}{c}0,0322 \text { a } 0,0426 \\
(0,0321 \text { a } 0,0456)\end{array}$ & $-2,8509$ & dentro & dentro & $C(+1972)$ \\
\hline $2 \mathrm{P}$ & $\begin{array}{c}3,5872 \\
(0,1706)\end{array}$ & $\begin{array}{c}0,5872 \\
(0,0641)\end{array}$ & $\begin{array}{c}2,8037 \text { a } 4,3707 \\
(0,0104 \text { a } 0,3308)\end{array}$ & 0,8573 & dentro & fora & NC \\
\hline $2 \mathrm{~V}$ & $\begin{array}{c}0,5138 \\
(0,5636)\end{array}$ & $\begin{array}{c}0,6684 \\
(0,5500)\end{array}$ & $\begin{array}{c}0,3796 \text { a } 0,6501 \\
(0,3938 \text { a } 0,7334)\end{array}$ & $-0,9152$ & dentro & dentro & $C(+1986)$ \\
\hline $3 T$ & $\begin{array}{c}0,0483 \\
(0,0562)\end{array}$ & $\begin{array}{c}0,7525 \\
(0,8796)\end{array}$ & $\begin{array}{c}0,0350 \text { a } 0,0616 \\
(0,0273 \text { a } 0,0452)\end{array}$ & $-1,5802$ & dentro & dentro & $C(+1993)$ \\
\hline $3 P$ & $\begin{array}{c}0,9130 \\
(0,9360)\end{array}$ & $\begin{array}{c}0,9615 \\
(0,5538)\end{array}$ & $\begin{array}{c}0,8377 \text { a } 0,9882 \\
(0,6477 \text { a } 1,2243)\end{array}$ & $-1,1554$ & dentro & fora & NC \\
\hline $3 \mathrm{~V}$ & $\begin{array}{c}-0,0101 \\
(-0,1302)\end{array}$ & $\begin{array}{c}0,6792 \\
(0,2715)\end{array}$ & $\begin{array}{c}-0,1303 \text { a }-0,0728 \\
(-0,2034 \text { a }-0,0570)\end{array}$ & $-1,4573$ & dentro & fora & NC \\
\hline $4 \mathrm{~T}$ & $\begin{array}{c}0,3621 \\
(0,2241)\end{array}$ & $\begin{array}{c}0,6935 \\
(0,0949)\end{array}$ & $\begin{array}{c}0,2888 \text { a } 0,4351 \\
(0,0353 \text { a } 0,4130)\end{array}$ & $-2,0702$ & dentro & fora & NC \\
\hline $4 \mathrm{P}$ & $\begin{array}{c}0,0393 \\
(0,0426)\end{array}$ & $\begin{array}{c}0,6234 \\
(0,1100)\end{array}$ & $\begin{array}{c}-0,0031 \text { a } 0,0818 \\
(-0,0336 \text { a } 0,1190)\end{array}$ & 0,1335 & dentro & fora & NC \\
\hline $4 \mathrm{~V}$ & $\begin{array}{c}0,2179 \\
(0,2137)\end{array}$ & $\begin{array}{c}0,9484 \\
(0,7023)\end{array}$ & $\begin{array}{c}0,2023 \text { a } 0,2335 \\
(0,1754 \text { a } 0,2521)\end{array}$ & $-2,4316$ & fora & dentro & NC \\
\hline $5 T$ & $\begin{array}{c}0,0284 \\
(0,0255)\end{array}$ & $\begin{array}{c}0,9575 \\
(0,3765)\end{array}$ & $\begin{array}{l}0,0215 \text { a } 0,03531 \\
(0,0074 \text { a } 0,0435)\end{array}$ & $-1,1713$ & dentro & fora & NC \\
\hline $5 P$ & $\begin{array}{c}0,0744 \\
(-0,1221)\end{array}$ & $\begin{array}{c}0,0139 \\
(0,0176)\end{array}$ & $\begin{array}{c}-0,1052 \text { a } 0,2541 \\
(-0,3597 \text { a } 0,1155)\end{array}$ & 0,8573 & dentro & dentro & $C(-1983)$ \\
\hline $5 \mathrm{~V}$ & $\begin{array}{c}0,1764 \\
(0,2485)\end{array}$ & $\begin{array}{c}0,7209 \\
(0,4972)\end{array}$ & $\begin{array}{c}0,1279 \text { a } 0,2249 \\
(0,1585 \text { a } 0,3385)\end{array}$ & $-3,7292$ & fora & dentro & NC \\
\hline
\end{tabular}




\subsection{POSSÍVEIS CORRELAÇÕES ENTRE RELAÇÕES ANTRÓPICAS E AS VARIÁVEIS HIDRO- CLIMÁTICAS}

Com o intuito de relacionar os testes estatísticos apresentados anteriormente para a verificação da ocorrência de tendência com a influência de atividades antrópicas, como o impacto causado pelo funcionamento de barragens, desmatamentos florestais e crescimento populacional nessa região, foram realizados estudos referentes a possíveis correlações dessas atividades com as variáveis hidro-climáticas de interesse.

\subsubsection{BARRAGENS}

Com o passar dos anos mais de uma dezena de barragens e eclusas foram construídas ao longo de todas as sub-bacias hidrográficas do rio Tietê para suprir a produção de energia elétrica para diversas cidades do estado de São Paulo (CBDB, 2012) e dinamizar o fluxo de mercadorias e produção agrícola pelo transporte fluvial. Entretanto, a construção das mesmas disseminou mudanças drásticas na paisagem natural, traduzindo em certos impactos ambientais. A Figura 1 mostra a localização das barragens presentes ao longo do rio Tietê. A Tabela 3 apresenta os locais estudados e as barragens que se encontram mais próximas dos mesmos, além do ano de início de operação. Adicionalmente a essas informações, a tabela lista a área total do município e da vegetação natural com a porcentagem de cobertura vegetal desta e a ocorrência ou não da tendência diante dos testes estatísticos aplicados (Tabela 2).

Para o município de Araçatuba, a precipitação pluviométrica teve crescimento a partir do ano de 1972, como pode ser comprovado na Figura 6b e a vazão a partir de 1975. Constatou-se que as análises para esta localidade em termos da vazão acompanhou o comportamento da precipitação. Identificou-se que, desde o início de operação da "UHE Mário Lopes Leão" ocorrida em 1977, houve um crescimento do índice de vazão que pode estar relacionado ao represamento das águas neste trecho do rio.

Para Tatuí, em que pese o início de operação da "Barragem Porto Goes" ter ocorrido em 1928, o aumento do índice de precipitação se deu a partir do ano de 1980, assim como a vazão teve aumento após 1987, não sendo possível vincular a influência dessa barragem com os parâmetros hidro-climáticos aqui estudados.

Em Mogi das Cruzes, o início de operação da "Barragem Ponte Nova" deu-se em 1971. Ao analisar o índice de precipitação nesta localidade, percebeu-se que ocorreu o crescimento desse parâmetro entre 1971 a 1984, em seguida decresceu até 1991, com algumas flutuações até 1993 e, a partir de 1995, em geral esse índice decresceu, mantendo constante entre 1995 a 1997. Em contrapartida, o índice de vazão cresceu entre 1973 a 1982, permanecendo estável até 1991, a partir daí iniciou o declínio. Aparentemente, o índice de vazão acompanhou o comportamento do nível da precipitação, o que evidencia que a operação da barragem influenciou nos comportamentos dessas variáveis.

De forma análoga, no município de Reginópolis a precipitação teve crescimento a partir de 1972 e a vazão a partir de 1973 (Figura 7b). Constatou-se que o índice de vazão seguiu o mesmo padrão do índice de chuva, corroborando com o início de operação da "UHE Álvaro de Souza Lima", verificado em 1969. 
No que concerne ao município de Araraquara, não se constatou qualquer vínculo entre os parâmetros hidro-climáticos analisados, o que indica não haver qualquer correlação entre eles e o início de operação da "UHE Bitinga".

Tabela 3 - Barragens localizadas no rio Tietê e o ano de início de operação. Área total, área com vegetação natural e porcentagem da cobertura vegetal natural do município, além das tendências dos parâmetros hidro-climáticos estudados (CBDB, 2011; INVENTÁRIO, 2005).

\begin{tabular}{|c|c|c|c|c|c|c|}
\hline Município & $\begin{array}{c}\text { Barragem mais } \\
\text { próxima }\end{array}$ & $\begin{array}{l}\text { Ano de inicio } \\
\text { de operação } \\
\text { da barragem }\end{array}$ & $\begin{array}{l}\text { Área } \\
\text { total } \\
\text { (ha) }\end{array}$ & $\begin{array}{c}\text { Área com } \\
\text { vegetação } \\
\text { natural } \\
\text { (ha) }\end{array}$ & $\begin{array}{c}\% \text { da } \\
\text { cobertura } \\
\text { vegetal } \\
\text { natural }\left({ }^{*}\right)\end{array}$ & Tendências \\
\hline Araçatuba & $\begin{array}{l}\text { UHE(**) Mário } \\
\text { Lopes Leão }\end{array}$ & 1977 & 116800 & 1.681 & $1,4 \%$ & $\begin{array}{l}T(N C) \\
P(N C) \\
V(N C)\end{array}$ \\
\hline Tatuí & $\begin{array}{l}\text { Barragem de } \\
\text { Porto Goes }\end{array}$ & 1928 & 52100 & 2.588 & $5 \%$ & $\begin{array}{c}\mathrm{T}(\mathrm{C}+1972) \\
\mathrm{P}(\mathrm{NC}) \\
\mathrm{V}(\mathrm{C}+1986)\end{array}$ \\
\hline $\begin{array}{l}\text { Mogi das } \\
\text { Cruzes }\end{array}$ & $\begin{array}{c}\text { Barragem Ponte } \\
\text { Nova }\end{array}$ & 1971 & 73100 & 16.650 & $22,8 \%$ & $\begin{array}{c}\mathrm{T}(\mathrm{C}+1993) \\
\mathrm{P}(\mathrm{NC}) \\
\mathrm{V}(\mathrm{NC})\end{array}$ \\
\hline Reginópolis & $\begin{array}{l}\text { UHE Álvaro de } \\
\text { Souza Lima }\end{array}$ & 1969 & 40500 & 3.174 & $7,8 \%$ & $\begin{array}{l}T(N C) \\
P(N C) \\
V(N C)\end{array}$ \\
\hline Araraquara & UHE Bitinga & 1969 & 101100 & 5.818 & $5,8 \%$ & $\begin{array}{c}T(N C) \\
P(C-1983) \\
V(N C)\end{array}$ \\
\hline
\end{tabular}

(*) relação entre a área vegetal e a área total do município.

$(* *)$ UHE - Usina Hidrelétrica.

\subsubsection{COBERTURA VEGETAL}

No entendimento de Nobre, Sellers e Shukla (1991), as mudanças na cobertura superficial de uma região podem acarretar em impactos significativos no clima regional. Em particular, o estado de São Paulo, por representar o centro econômico do país, espera-se encontrar constantes impactos ambientais por conta da urbanização acelerada, entre outros fatores. Dentre os diversos problemas identificados, pode-se citar a retirada da cobertura vegetal, explicada pelo aspecto evolutivo do desmatamento para abrigar novas áreas de plantio, ou de pecuária, ou ainda do crescimento urbano. Nas laterais da Figura 8 é reproduzido, a partir do Inventário Florestal da Vegetação Natural do Estado de São Paulo (INVENTÁRIO, 2005), a evolução das áreas desmatadas do território paulista desde uma situação primitiva (parte superior esquerda da figura) até o final do século passado (mapa inferior à direita). Destaca-se que apenas 3\% da cobertura vegetal original do estado de São Paulo mantiveram-se intactas até o ano de 2000.

A devastação de mata nativa de uma região, dependendo de sua amplitude, pode gerar impactos ambientais, ocasionando mudanças no ciclo hidrológico da região. A retirada da cobertura vegetal modifica a infiltração de água no solo, influenciando também nas vazões de rios, e até mesmo nas chuvas por conta da diminuição da evapotranspiração que é uma função das árvores e plantas. Além disso, sem a presença da floresta nativa não ocorre o processo de regulação térmica, podendo alterar as temperatura da região. A destruição da mata ciliar, em 
médio e longo prazo, pode diminuir a capacidade de armazenamento de água da sub-bacia, alterando o regime de vazão dos rios ali existentes (ANA, 2011).

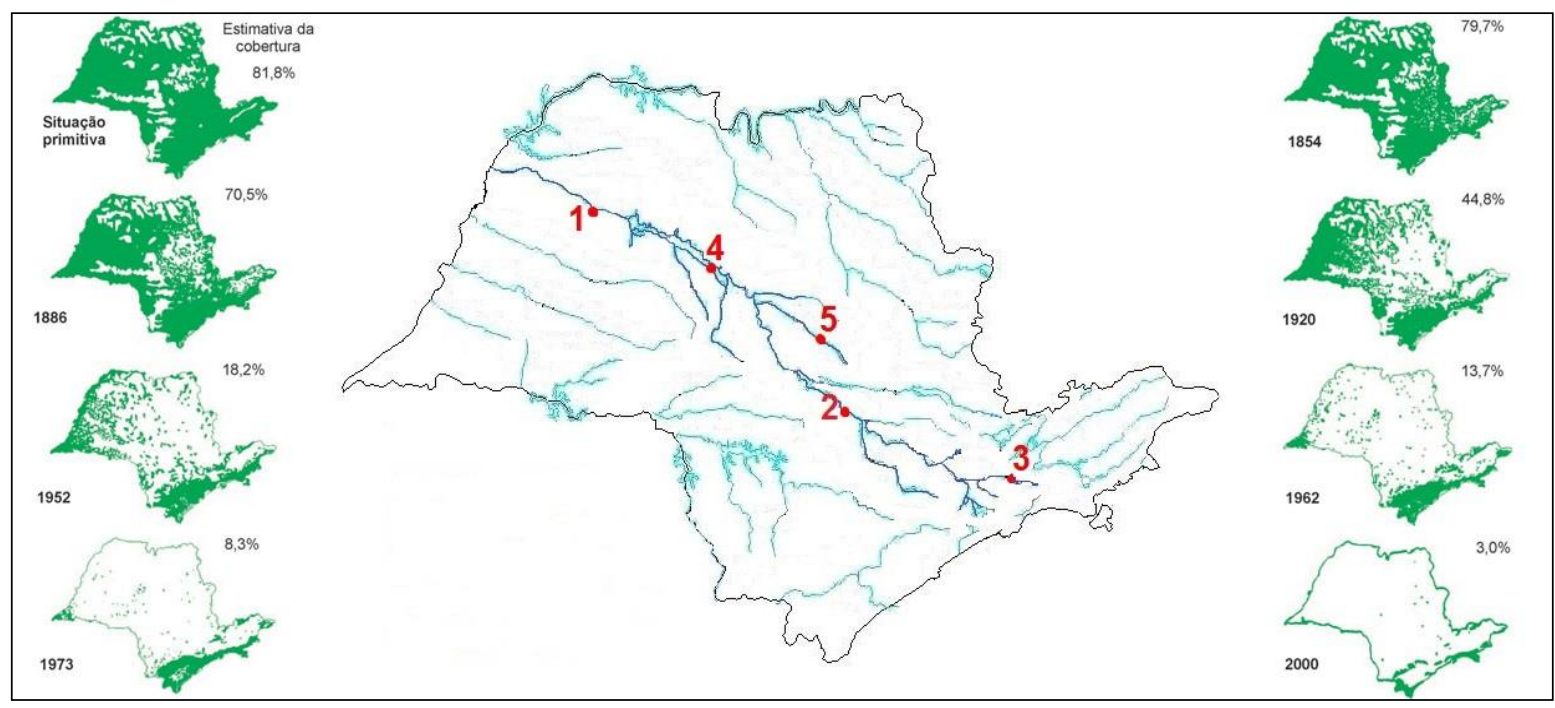

Figura 8 - Progressão do desmatamento no Estado de São Paulo (adaptado de: INVENTÁRIO, 2005).

A Tabela 3 revela que o município de Mogi das Cruzes possui a maior porcentagem de cobertura vegetal remanescente quando comparada aos dos demais municípios paulistas, totalizando $22,8 \%$ da área de vegetação natural. É possível observar pela Figura 8 que no ano de 1973 a porcentagem de cobertura vegetal do estado era de 8,3\%, diminuindo drasticamente para $3 \%$ no ano de 2000. Analisando os parâmetros hidro-climáticos para essa localidade, pode-se afirmar que em geral o índice de vazão seguia o comportamento do índice de precipitação até o ano de 1995, porém após esse período os comportamentos dessas medidas inverteram-se. Talvez esse fato esteja relacionado com a excessiva porcentagem de desmatamento ocorrida nas últimas décadas. Em relação a temperatura média do ar, até o ano 1995, esse índice era de decrescimento e, em seguida, iniciou o crescimento. Presume-se que esse fato também esteja relacionado com a diminuição da cobertura vegetal no ano 2000 , devido ao avanço industrial da área urbana desse município.

Para as demais localidades consideradas com pequena porcentagem de vegetação natural, em geral, o índice de temperatura média do ar apresenta-se com crescimento, em particular após o ano 2000.

\subsubsection{CRESCIMENTO POPULACIONAL}

Numa tentativa de identificar a relação do comportamento dos parâmetros hidroclimáticos com a população de uma localidade, foram confeccionados gráficos referentes aos dados populacionais no período de 1940 a 2010, para as cinco localidades mencionadas neste trabalho usando as informações provenientes da SEADE (2012) e do IBGE (2013). Entretanto, os períodos obtidos para essas séries históricas não coincidem, o que dificulta a realização de uma análise mais acurada sobre a relação entre esses parâmetros e o crescimento populacional.

No caso das variáveis precipitação e vazão, em geral, apresentaram o mesmo comportamento, porém, aparentemente essas variáveis não se correlacionam com o crescimento populacional das cidades estudadas. As análises realizadas indicam que para os municípios de interesse a variável temperatura média do ar acompanha o crescimento 
populacional. Como ilustração a este fato, a Figura 9 mostra as análises realizadas para a cidade de Tatuí, apontando a evolução do crescimento da população e o comportamento com a precipitação na cidade (Figura 9 superior), com a vazão do rio Sorocaba (Figura 9 central) e com a temperatura mínima, média e máxima do ar (Figura 9 inferior).

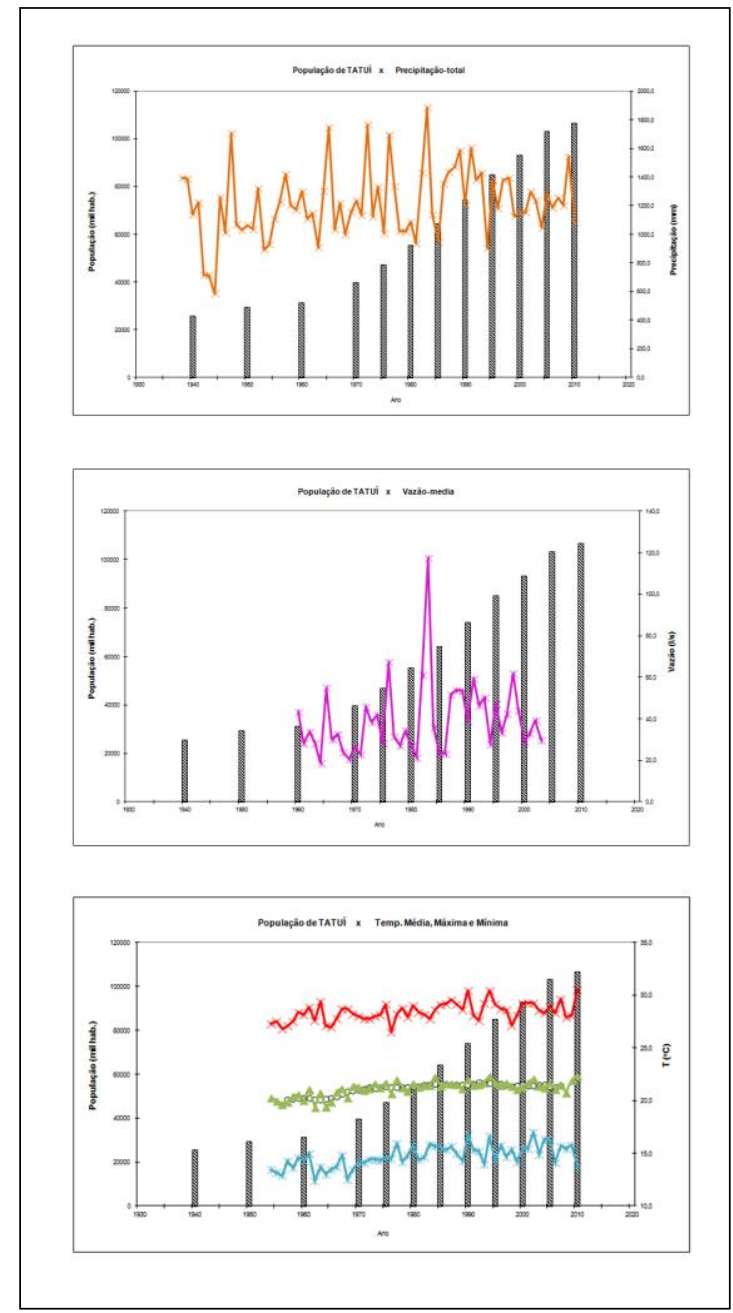

Figura 9- Crescimento populacional de Tatuí e os parâmetros precipitação (superior), vazão do rio Sorocaba (central) e temperatura mínima, média e máxima (inferior) entre o período de 1940 e 2010.

Averiguando as figuras superior e central, é possível notar que os índices de precipitação pluviométrica e de vazão apresentaram um destacado pico no ano de 1984. Após 1984, os índices de precipitação e vazão passaram a decrescer, enquanto a população da cidade sofreu um contínuo aumento. No tocante as variáveis temperaturas mínima, média e máxima (Figura 9 inferior), esses índices mostraram-se relativamente estável, em que pese o aumento da população durante o período de análises.

O presente exemplo, assim como os outros casos analisados ao longo desse estudo, revela as dificuldades encontradas para estabelecer qualquer correlação da população com os parâmetros hidro-climáticos de uma determinada localidade. 


\section{CONCLUSÕES}

O presente trabalho envolveu uma grande quantidade de informações extraídas da base de dados do IAC e SIGRH, nas sub-bacias hidrográficas do rio Tietê. O intuito foi verificar a ocorrência de possíveis tendências das grandezas hidro-climáticas por meio de testes estatísticos e adicionalmente, verificar se ocorreu algum impacto causado pelo desmatamento, aumento populacional e a construção de barragens sobre essas grandezas.

Analisando os resultados obtidos por meio das atividades exploratórias realizadas, podese observar que para as localidades estudadas por meio dos testes de $M K$ e $P$, as tendências confirmadas de crescimento ocorreram para as séries de temperatura média do ar na cidade de Tatuí no ano de 1972, de Mogi das Cruzes em 1993 e na vazão do rio Sorocaba (Tatuí) a partir de 1986. Entretanto, para a precipitação de Araraquara, identificou-se um decréscimo a partir do ano de 1983.

Comparando os valores obtidos nos testes estatísticos com as datas de início de operação e construção das barragens para a operação de usinas hidroelétricas nas proximidades desses locais, verificou-se que para os municípios de Araçatuba, Mogi das Cruzes e Reginópolis, os lagos formados por essas obras influenciaram nos índices de vazões dessas localidades.

Em que pese o município de Mogi das Cruzes possuir a maior porcentagem de área vegetal remanescente comparada aos demais municípios paulistas, o índice de vazão seguiu o comportamento da precipitação até o ano de 1995, entretanto, posterior a essa data, os comportamentos desses parâmetros inverteram-se. É possível que isto esteja relacionado a alta porcentagem de desmatamento ocorrida na região nas últimas décadas. Isso também pode estar associado ao aumento da temperatura média do ar nesta localidade.

Quanto a comparação dos parâmetros hidro-climáticos com o crescimento populacional, as análises realizadas indicam que as variáveis precipitação e vazão, em geral, apresentaram o mesmo comportamento. Aparentemente essas variáveis não se correlacionaram com o crescimento populacional das cidades estudadas, porém, verificou-se que a variável temperatura média do ar para as localidades trabalhadas acompanhou o padrão do crescimento da população.

Em geral, os resultados encontrados na aplicação dos testes estatísticos conseguiram capturar adequadamente o comportamento das informações hidro-climáticas disponíveis nos dados do IAC e SIGRH, a despeito das incertezas existentes, principalmente relacionadas a limitada quantidade de locais abordados. Mesmo assim, projeções de eventuais mudanças climáticas e hidrológicas são plausíveis, constituindo informações inovadoras e valiosas tanto para fins de mitigação, como planejamento de ações de adaptação e minimização de impactos e vulnerabilidade junto ao conjunto da sociedade que habita as regiões cortadas pelo rio Tietê.

\section{REFERÊNCIAS BIBLIOGRÁFICAS}

1. ANA. Agência Nacional de Águas. Disponível em http://www2.ana.gov.br. Acesso em 01 dez. 2011.

2. BACK, A. J. Aplicação de análise estatística para identificação de tendências climáticas. Pesquisa Agropecuária Brasileira, v. 36, n. 5, p. 717-726, 2001. 
3. CBDB. Comitê Brasileiro de Barragens. Disponível em http://www.cbdb.com.br. Acesso em $01 \mathrm{dez} .2012$.

4. CERVILHA, G. B.; FILHO, A. C. S. Métodos estocásticos e não estocásticos para a previsão de vazão em rios. Disponível em http://www.facef.br/novo/publicacoes/.../Guilherme\%20 Cervilha.pdf. Acesso em 25 out. 2011.

5. CHRISTOFOLETTI, A. Implicações climáticas relacionadas com as mudanças climáticas globais. Boletim de Geografia Teorética. Rio Claro, v. 23, n.45-46, p.18-31, 1993.

6. CIIAGRO. Centro Integrado de Informações Agrometeorológicas. Disponível em http://www.ciiagro.sp.gov.br. Acesso em 25 fev. 2012.

7. GOOSSENS, C.; BERGER, A. Annual and seasonal climatic variations over the northem hemisphere and Europe during the last century. Annales Geophysicae, Berlin, v. 4, n. B4, 1986.

8. GROPPO, J. D.; MILDE, L. C. E.; GUAMERO, M. E.; MORAES, J. M. MARTINELLI, L. A. Análise de séries temporais de vazão e precipitação na bacia do rio Piracicaba. Revista Ciência \& Tecnologia, v.8 n.18, p.109-117, 2001.

9. IBGE. Instituto Brasileiro de Geografia e Estatística. Disponível em: http://www.ibge. gov.br/home/mapa_site/mapa_site.php\#populacao. Acesso em: 20 fev. 2013.

10. INVENTÁRIO Florestal da Vegetação Natural do Estado de São Paulo. São Paulo: Secretaria do Meio Ambiente, 2005 - Instituto Florestal Imprensa Oficial, 2005. Disponível http://www.iflorestal.sp.gov.br/sifesp/publicacoes.html. Acesso em: 20 fev. 2013.

11. KARL, T. R.; DIAZ, H.F.; KUKLA, G. Urbanization: its detection and effect in the United States climate record. Journal of Climate, v.1, n.11, p.1099-1123, 1988.

12. MILLER, P. Deu a louca no tempo. National Geographic Brasil. Ano 13, n. 150, p. 90-111, setembro de 2012.

13. MORTATTI, J.; BORTOLETTO JÚNIOR, M. J.; MILDE, L. C. E.; PROBST, J. L. Hidrologia dos rios Tietê e Piracicaba: séries temporais de vazão e hidrogramas de cheia, Revista de Ciência \& Tecnologia, v. 12, n. 23, 2004.

14. NOBRE, C. A.; SELLERS, P. J.; SHUKLA, J. Amazonian deforestation and regional climate change. Journal of Climate, v. 4, n. 10, p. 957-987, 1991.

15. PENEREIRO, J. C.; FERREIRA, D. H. L. Estatística apoiada pela tecnologia: uma proposta para identificar tendências climáticas. Acta Scientiae, v.13 n.1, p. 87-105, 2011.

16. PETTITT, A. N. A non-parametric approach to the change-point problem. Applied Statistics, v. 28, n. 2, p.126-13, 1979.

17. SALATI, E.; SANTOS, A. A.; NOBRE, C. As mudanças climáticas globais e seus efeitos nos ecossistemas brasileiros., 2004. Disponível em http://www.comciencia.br/reportagens/ clima/clima14.htm. Acesso em 26 jul. 2012.

18. SEADE. Fundação Sistema Estadual de Análise de Dados. Disponível em: http://www.seade .gov.br/produtos/500anos/. Acesso em: 17 dez. de 2012.

19. SELLO, S. Time series forecasting: a nonlinear dynamics approach, 1999. Disponível em: http://arxiv.org/abs/physics/9906035. Acesso em: 21 jun. 2010. 
20. SERRA FILHO, R.; CAVALLI, A. C.; GUILLAUMON, J. R.; CHIARINI, J. V.; NOGUEIRA, F. P.; IVANCKO, C. M. A. M.; BARBIERI, J. L.; DONIZELI, P. L.; COELHO, A. G. S.; BITTENCOURT, I. Levantamento da cobertura vegetal natural e do reflorestamento no Estado de São Paulo. Boletim Técnico do Instituto Florestal, v.11, p.1-56, 1975.

21. SIGRH. Sistema de Informações para o Gerenciamento de Recursos Hídricos do Estado de São Paulo. Disponível em http://www.sigrh.sp.gov.br. Acesso em 23 ago. 2011.

22. SNEYERS, R.; VANDIEPENBEECK, M.; VANILIERDE, R.; DEMAREE, G. R. Climatic changes in Belgium as appearing from the homogenized series of observations made in Brussels - Uccle (1933-1988) In: SCHIETECAT, G. D. (Ed.). Contributions à l'etude des changements de climat. Bruxelles: Institut Royal Meteorologique de Belgique, Publications Série 124, p. 17-20, 1990.

23. SNEYERS, R. Sur l'analyse statistique des séries d'observations. Genève: Organisation Meteorologique Mondial, 192 p. (OMM Note Technique, 143), 1975.

24. THOM, H. C. S. Some methods of climatological analysis. Genève: World Meteorological Organization, 54p. (WMO Technical Note, 81), 1966.

25. VAREIJÃO-SILVA M. A. Meteorologia e Climatologia. 2.ed. Brasília: INMET, 2001.

26. VIEIRA, S. R.; CARVALHO, J. R. P. Estudo da periodicidade temporal de chuvas em bacia hidrográfica dos Rios Turvo/Grande - uma proposta. Campinas: Embrapa Informática Agropecuária, 17 p. (Documentos, 10), 2001. 